\title{
Die Skelettreste aus dem Grabe J.C.Lavaters (1741-1801)
}

\section{Von Hans-Ueli Fritz Etter}

Im Zusammenhang mit den Renovationsarbeiten an der Sankt-Peter-Kirche in Zürich sind auch die Skelettreste unter der Grabplatte von Lavater gehoben worden $^{1}$ (s. Zeitschrift für Schweizerische Archäologie und Kunstgeschichte 33/1 (1976) 1-59).

\section{Fundmaterial}

Das Skelettmaterial umfaßte Reste von mindestens drei menschlichen Individuen $(A, B, C)$ und einem Tier (D).

\subsection{Skelett $A$}

- mehr oder weniger vollständiger Schädel, in der linken Schläfengegend stark beschädigt, mit Unterkiefer (Abb.1-4)

- Wirbelsäule, bestehend aus 6 teilweise stark beschädigten Halswirbeln, 7 vereinzelt stark beschädigten Brustwirbeln, 5 gut erhaltenen Lendenwirbeln, einem proximalen Kreuzbeinfragment

- 10 rechte und 9 linke Rippenstücke sowie mehrere Fragmente

- linkes und rechtes, stark beschädigtes Hüftbein

- Schlüsselbeine (rechts und links)

- Schulterblätter (rechts und links)

- Oberarmknochen (rechts und links)

- Speichen (rechts und links) ohne distale Epiphysen

- Ellen (rechts und links) ohne distale Epiphysen

- Handknochen (Metacarpalia II, III, IV links, IV rechts, proximale Phalanx I)

- Oberschenkelknochen (rechts vollständig, links ohne distale Epiphyse)

- Schienbeine (rechts ohne distale Epiphyse, links vollständig)

- Wadenbeine (rechts vollständig, links einzelne Bruchstücke)

- Fußknochen (Metatarsalia II-V links, I-V rechts, proximale Phalanx IV, Calcaneus links, Naviculare, Calcaneus, Talus, Cuneiforme III, Cuboideum rechts)

\subsection{Skelett $B$}

- rechter Talus

- distale Hälfte des linken Schlüsselbeines

- Metatarsalfragment

alles kindlich 


\subsection{Skelett $C$}

- Metatarsale II rechts, adult

\subsection{Skelett D}

- eine linke Unterkieferhälfte eines kleinen Wiederkäuers

In der Folge wird nur das unter 1.1 aufgeführte Skelett A besprochen.

\section{Geschlechtsbestimmung}

Die für eine Geschlechtsdiagnose wichtigen Skelettelemente sind teilweise gut erhalten (Schädel, Langknochen), teilweise fragmentiert (Becken).

Am Schädel finden sich keine ausgesprochen männlichen Merkmale. Die Mehrzahl der entscheidenden Merkmale sind im Gegenteil als eher weiblich zu bezeichnen (Glabella, Inion, Orbitae, Profilverlauf des Frontale, Processus mastoideus, Planum nuchale, Squama temporalis, Corpus mandibulae). Dasselbe gilt für die grazilen Langknochen. Auch am Becken sind keine Merkmale ausgebildet, die zwingend auf männlich hindeuten.

Insgesamt betrachtet, handelt es sich mit hoher Wahrscheinlichkeit um das Skelett eines weiblichen Individuums. Dies wurde auch durch die Untersuchungen von Lengyel (1976) bestätigt.

\section{Altersbestimmung}

Die für eine Altersbestimmung wichtigen Skelettelemente sind teilweise gut (Schädel, Langknochen, Wirbel), teilweise fragmentarisch (Becken) erhalten oder fehlen (Brustbein).

Am Schädel führen die für eine Altersbestimmung wichtigen Merkmale zu unterschiedlicher Beurteilung. Mit Sicherheit handelt es sich jedoch um ein erwachsenes Individuum. Der Zustand der Schädelnähte weist auf ein geringeres Alter hin als der Befund an den Zähnen und den übrigen Merkmalen. Die Situation am postcranialen Skelett stimmt besser mit den Zahnbefunden als mit dem Zustand der Schädelnähte überein. Nach der Methode von Nemeskéri et al. (1960) kann das Alter auf Grund der Spongiosastruktur am Humerus mit 44,8 bis 59,8 $(\mathrm{M} \pm 3 \mathrm{~s})$ Jahren und am Femur mit 36,2 bis 51,8 (M $\pm 3 \mathrm{~s})$ Jahren angegeben werden. Diese Angaben stimmen ziemlich gut überein mit anderen Befunden am postcranialen Skelett. Der Zustand der Zähne und der Wirbelkörper läßt jedoch ein eher höheres Alter vermuten. 
Die von Lengyel (1976) durchgeführten Laboruntersuchungen deuten auf dieselbe Problematik hin ${ }^{2}$. Nach ihm ergeben 3 der chemischen Werte $\left(\mathrm{CO}_{3}, \mathrm{P}\right.$, Ca) ein Alter zwischen 61 und 70 Jahren. Daß der Collagen-Wert allerdings auf ein Alter von 41 bis 50 Jahren hindeutet, glaubt Lengyel mit den pathologischen Befunden aus der Silber-Imprägnierung erklären zu können. Damit decken sich die durch die chemischen und anthropologischen Untersuchungen gewonnenen Befunde weitgehend.

\section{Körpergröße}

Auf Grund der Umrechnungstabellen von Breitinger (1937) und Bach (1965) für die aus Langknochen ermittelten Körpergrößen ergeben sich für ein männliches Individuum 156,8 $\pm 4 \mathrm{~cm}$ (klein) und für ein weibliches Individuum 154,8 $\pm 4 \mathrm{~cm}$ (mittelgroß). Die Angaben sind aus drei Werten (Humerus, Femur, Tibia) gemittelt.

\section{Pathologie}

An fast allen Wirbeln sind Anzeichen von Exostosen zu erkennen. Insbesondere weisen die unteren Halswirbel- und die oberen Brustwirbelkörper deutliche Randwulstbildungen auf, was auf einen Altersbuckel hindeuten könnte. Die wenigen noch vorhandenen Zähne (oben: M2, M1, P2/M1, unten: M2, M1, P2, P1/P1, M1, M2) sind stark kariös. Zudem deuten teilweise oder ganz verschlossene Alveolen (oben: M3, I2, I1/I1, I2, C, M3, unten: M3, I1/I1, I2 M3) darauf hin, daß dem Individuum in seiner letzten Lebensphase das Vordergebiß nahezu vollständig gefehlt hat. Im Bereiche des rechten oberen Caninus sind Spuren eines Alveolarabszesses zu sehen.

\section{Morphologie}

Das ganze postcraniale Skelett ist auffallend grazil gebaut. Dies trifft in gleichem Maße auch für den Schädel (Abb.1, 2) zu. Bei Oberansicht ist er oval geformt und zeigt ausgeglichene Dimensionen (Längenbreitenindex 84,8, brachycran). Die Mitte des Scheitels ist bei Seitenansicht nur schwach, bei Vorderansicht mäßig stark durchgebogen. Das Hinterhaupt ist stark gerundet und deutlich abgesetzt. Der Hinterkopf ist insgesamt als niedrig zu bezeichnen.

Das Gesicht ist weder hoch noch breit (Gesichtsindex 89,7, mittelhoch), aber fein durchgearbeitet. Die Stirn ist eher niedrig und im Profil steil. Ein Überaugenwulst fehlt fast vollständig. Die Nasenwurzel ist kaum eingezogen. Über den Verlauf der Nasenprofillinie lassen sich keine Angaben machen, da die Nasen- 
beine fehlen. Insgesamt ist die Nase aber schmal und hoch (Nasalindex 45,6, schmalnasig). Die Orbitae sind rundlich, die Achsen unauffällig stark nach außen unten geneigt. Auch der Oberrand der Orbitae verläuft nach außen unten. Die Wangenbeine sind weder ausladend noch vorspringend. Der Unterkiefer ist grazil mit niedrigem Unterkieferkörper und wenig betonter Unterkieferwinkelgegend.

7. Metrik (nach Martin/Saller, 1957)

\begin{tabular}{|c|c|c|}
\hline Humerus & ganze Länge & $273 \mathrm{~cm}$ \\
\hline Humerus & ganze Länge & $275 \mathrm{~cm}$ \\
\hline Tibia & ganze Länge & $308 \mathrm{~cm}$ \\
\hline Femur & ganze Länge & $394 \mathrm{~cm}$ \\
\hline Fußlänge & (errechnet aus Mittelfußlänge) & $21 \mathrm{~cm}$ \\
\hline \multirow[t]{7}{*}{ Schädel } & Länge & $173 \mathrm{~cm}$ \\
\hline & Breite & $146 \mathrm{~cm}$ \\
\hline & Jochbogenbreite & $122 \mathrm{~cm}$ \\
\hline & Gesichtshöhe & $110 \mathrm{~cm}$ \\
\hline & Obergesichtshöhe & $62 \mathrm{~cm}$ \\
\hline & Nasenbreite & $21 \mathrm{~cm}$ \\
\hline & Nasenhöhe & $47 \mathrm{~cm}$ \\
\hline \multirow[t]{4}{*}{ Indices: } & Längenbreitenindex & 84,8 brachicran \\
\hline & Gesichtsindex & 89,7 mittelhoch \\
\hline & Obergesichtsindex & 51,0 mittelhoch \\
\hline & Nasalindex & 45,6 schmalnasig \\
\hline
\end{tabular}

\section{Diskussion}

Auf Grund der anthropologischen Bearbeitung ergab sich beim vorliegenden Skelett das Bild eines kleinen, fein gebauten Individuums mit deutlich weiblicher Merkmalsausprägung, das im 4. oder 5.Lebensjahrzehnt gestorben ist. Nebst stark kariösen Zähnen sind Exostosen im Bereich der Wirbelsäule zu finden. Weitere pathologische Befunde sind nicht festzustellen.

Dieses Bild steht teilweise in krassem Widerspruch zu dem Bild, das Zeitgenossen, Freunde und Bekannte von Lavater entworfen haben.

Lavater scheint ein eher groß gewachsener, aber fein gebauter Mann gewesen zu sein. Er starb 1801 in seinem 60. Lebensjahr an den späten Folgen einer Schußverletzung (Bodemann, 1856). Aus dem Sektionsbericht (Abb.5) geht hervor, daß die Kugel, die ein unbekannter helvetischer Grenadier $5 / 4$ Jahre vor seinem Tode auf ihn abgefeuert hatte (Lavater, 1799), zwischen der 7. und 8. Rippe rechts eingedrungen ist. Sie wurde kurze Zeit nach dem Zwischenfall von Diethelm 


\section{Rabaters Section.}

Sie allgemeine gutmittfige Nennung: „2A

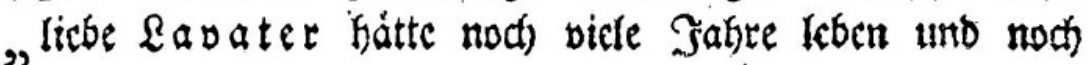
"10 vicles Butte ftiften tonnten, hatte inn nid) jener unt

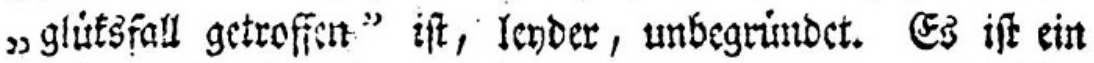
betrubtar Troft, aber bod) cin Troft, daf ber aldgeficbto Lavater auch ofjne jencs funglúf fein alter nidjt viel

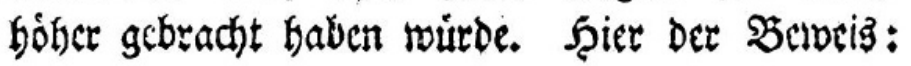

Sin Der Eection fand man, !Daf Er auth, obne bie

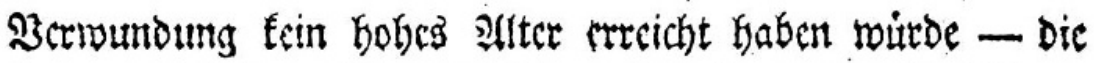

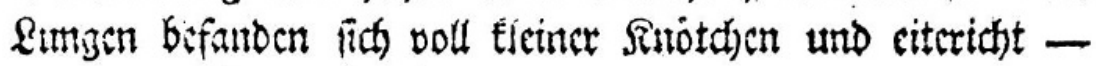
bie rechte Sunge befonders mar ganj feft mit ber Stuft: mentbran berwarchen, uab ganj oben gegen Den 2leftert

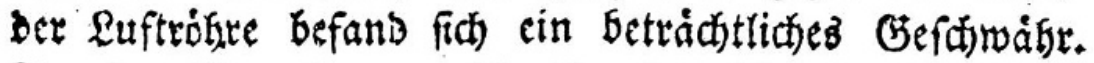
Ber) Der Stegend, wo bie Siugel auf ber redten Eeite

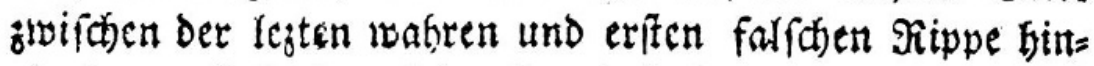
eingieng, befanhen fidh widernatürliche Berfnorplungen; Der Seinfraf Gatte diefe Rippen vom Bruftecine Yosge = freffen, bie fith bey jebem $\Re$ eis zum Salten mit groffem Samers furdthat berwegten; auf ber linten Seite batte

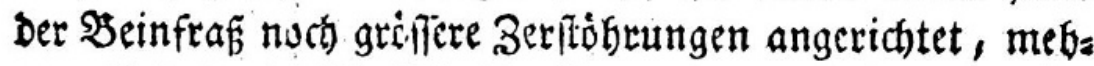
rere tiefgethende fiftulófe Eanále wurben entbeft, und be=

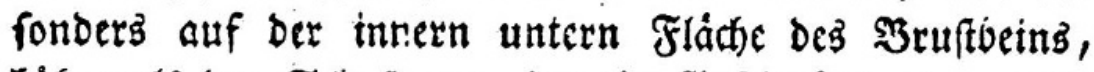

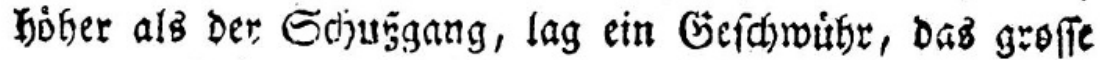
und merfwurbige Bectitofrungen in biefem Rnod)en ange zichtet und benlelben ourchfreffen batte. Diés war die Stelle, wo er hábri beftánbigen burch) nichts zu mildernden Samerz flagte; whe baf man von aufien ben Sanden unterfuchea docr ertennen fonnte. Die übrigen Tbeile Deş Riorpers waren bơllig gefund.

Abb.5. Sektionsbericht über J.C.Lavater. Der Druck ist unbekannter Herkunft und den Aufzeichnungen «Über Lavaters Krankheit und Tode 1801 » eines unbekannten Autors entnommen 
Lavater, seinem Bruder und Leibarzt, entfernt. Aus dem Sektionsbericht (Abb.5) geht weiter hervor, daß Rippen und Brustbein vom Beinfraß (Gangraena ossis) ${ }^{3}$ befallen waren. An keiner Rippe des vorliegenden Skelettes (das Brustbein fehlt) sind direkte Einwirkungen einer Schußverletzung oder gangränöse Veränderungen feststellbar. Die leicht grünliche Verfärbung an der 5. und (wahrscheinlich) 6. Rippe rechts kann nicht mit den direkten oder indirekten Auswirkungen der Schußverletzung in Zusammenhang gebracht werden. Wahrscheinlich handelt es sich dabei um die Spuren aus der Zersetzung eines metallischen Gegenstandes, der in dieser Gegend lag (z. B. kleine Schnalle des Leichenhemdes).

Da es sich bei Lavater um eine historisch bedeutsame Persönlichkeit der Stadt Zürich und um einen europäisch bekannten Physiognomen handelte, sind von ihm zahlreiche Schattenrisse, Zeichnungen und Stiche angefertigt worden ${ }^{4}$. Dies gestattet, seine Profilkonturen mit den Profilkonturen des vorliegenden Schädels (Abb.1) zu vergleichen. Es ist bekannt, daß das Unterhautgewebe in der mediansagittalen Ebene im Bereiche der Nasenwurzel, des Ủberaugenwulstes und der Stirne keinen wesentlichen Dickenveränderungen unterworfen ist (Gerassimov, 1968). Demzufolge müßte die Profillinie in den Porträts von Lavater mindestens in diesem Bereiche mit der Profillinie des vorliegenden Schädels ausreichend gut übereinstimmen. Zu Vergleichszwecken sind aus etwa 150 Porträts drei unterschiedliche verwendet worden: ein Altersporträt (Abb.6), ein Selbstporträt (Abb. 7) und ein Schattenriß (Abb.8). In zwei Bilder sind die Umrisse des Schädels in der richtigen Größe und Lage eingepaßt (Abb.6,7). Beim Schattenriß ist der Schädel den Umrißlinien des Bildes eingepaßt (Abb.9). In den folgenden Merkmalen stimmt der Schädel nicht mit den Profillinien der Bilder überein: zuwenig vorspringendes Kinn, zu niedriges Kinn, zu tief liegende Orbitae, zuwenig tief eingezogene Nasenwurzel, zuwenig prominente Glabella, zu steile Stirn, zuwenig ausladendes Hinterhaupt, zu niedriger Hirnkopf.

Auf Grund der zahlreichen Widersprüche zwischen den am Skelett ermittelten Merkmalen und den historischen Angaben über J. C. Lavaters Person (Geschlecht, Körpergröße, Pathologie, Morphologie des Kopfes) ist mit an Sicherheit grenzender Wahrscheinlichkeit anzunehmen, daß die dem Grabe Lavaters an der Nordmauer der Sankt-Peter-Kirche entnommenen Gebeine nicht die sterblichen Überreste von J. C. Lavater sind.

Dieser Befund war überraschend, denn von der Fundsituation her haben sich keine Zweifel an der Identität der Gebeine erhoben. Lavaters Grabstätte auf dem SanktAnna-Friedhof (Abb. 10), wo er am 5. Januar 1801 beigesetzt worden ist, wurde im Herbst 1881 aufgehoben, wobei seine Überreste gesammelt und, in einem Holzschrein verwahrt, der Kirchenpflege St. Peter übergeben worden sind (Abb.11). 


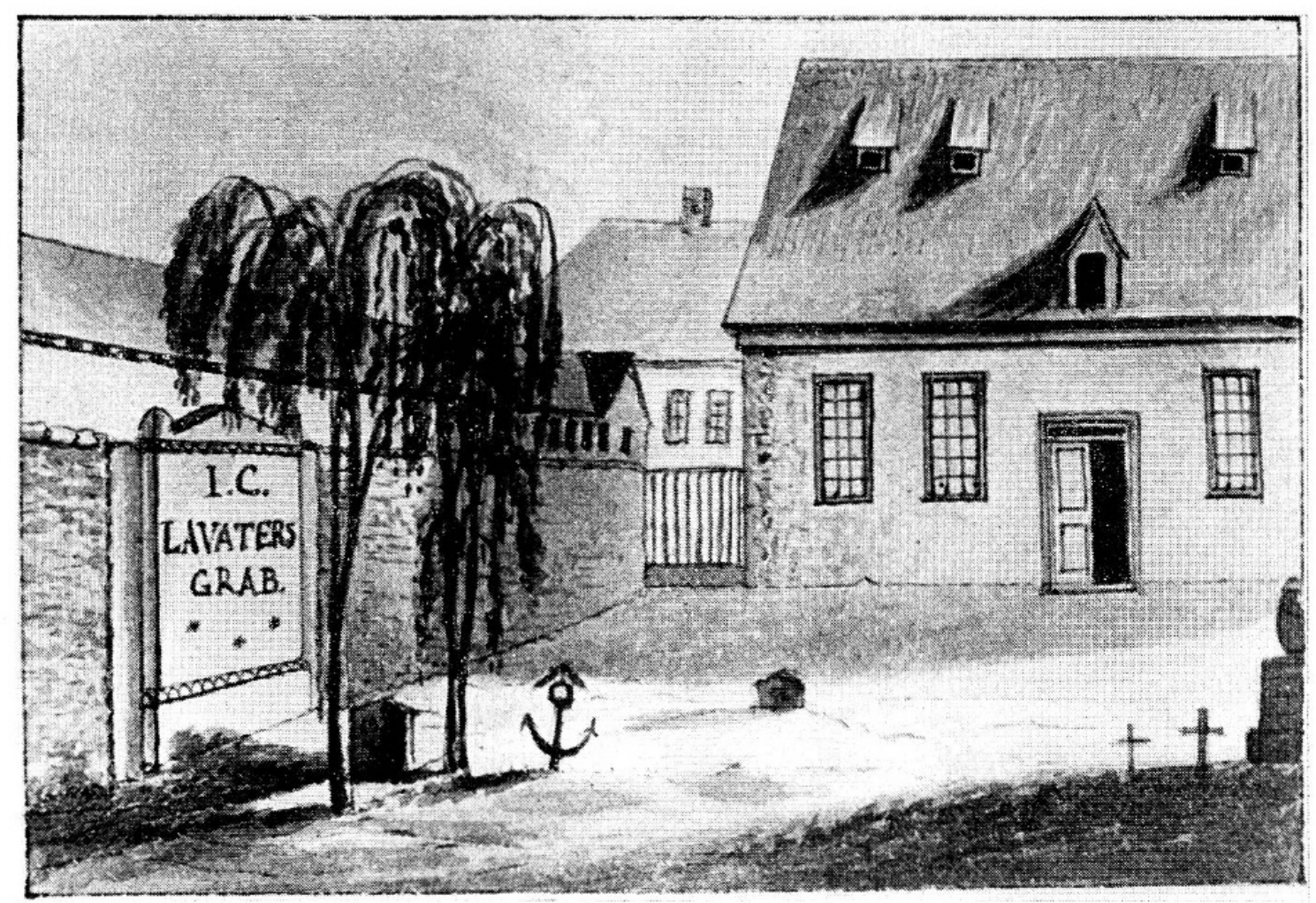

Abb. 10. Lavaters Grab auf dem SanktAnna-Friedhof, aquarellierte Zeichnung von Johann Heinrich Meyer, Graphische Sammlung der Zentralbibliothek Zürich. Mit der Aufhebung dieses Friedhofes sind die Gebeine J.C. Lavaters ergraben und der Kirchenpflege St.Peter übergeben worden

Abb.11. Lavaters Ehrengrab an der Nordmauer der Sankt-Peter-Kirche in Zürich, das 1882 errichtet wurde und aus dem 1973 der Holzschrein mit den menschlichen Skelettresten gehoben worden ist

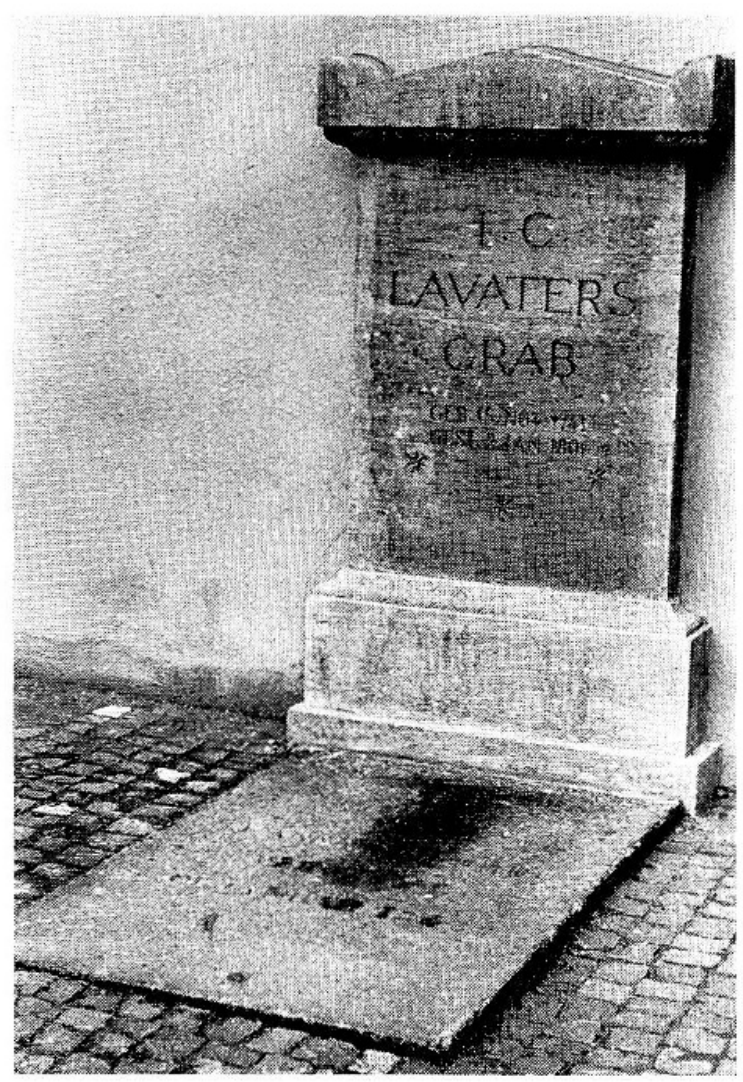


«Der Schädel des bedeutenden Mannes ist ziemlich klein, aber überaus wohlgestaltet und in allen Partien, man kann sagen, harmonisch geformt. Die Augenhöhlen sind auffallend groß. Das Nasenbein erstreckt sich ziemlich tief gegen den Oberkiefer hinab und entspricht so der Gesichtsform, wie sie die bekannten Portraits zeigen...», steht in der NZZ vom 6. Januar 1882 zu lesen. Dies gibt zur berechtigten Annahme Anlaß, der betreffende Journalist habe den authentischen Schädel Lavaters vor der neuen Beisetzung an der Nordmauer der Sankt-PeterKirche gesehen.

Es erhob sich nun die Frage nach der wahren Identität des vorliegenden Skelettes. Ein Hinweis seitens der Pfarrei der Sankt-Peter-Kirche, wonach es sich sehr wohl um die Reste von Lavaters Frau, Anna Lavater-Schinz (1747 bis 1815), handeln könne, bewirkte einen Vergleich der anthropologischen Daten mit den nur spärlich vorhandenen Daten zur Person von Frau Lavater.

Weder die Angaben über das Geschlecht noch über die Körpergröße führten zu Widersprüchen, wobei allerdings kaum verwertbare Hinweise zur Körpergröße von Frau Lavater existieren. Lediglich aus Familienbildern ist zu entnehmen, daß sie eher klein war. Sie starb am 24.9.1815 in ihrem 73. Lebensjahr. Dieses Alter weicht von dem am Skelett ermittelten Alter ab. Allerdings war die Bestimmung des Skelettalters nicht unproblematisch, streut es doch je nach Merkmal erheblich (s.o.), so daß ein Ausschluß allein auf Grund des Alters nicht gerechtfertigt erscheint. Zudem war Frau Lavater kränklich und häufig bettlägerig. Ihr Tochtermann Georg Geßner schreibt, daß seine Schwiegermutter die Hälfte ihres Lebens krank zugebracht hätte (Geßner, 1836). Dies könnte die durch mechanische Abnützung beeinflußten Altersmerkmale als jünger erscheinen lassen. In ihren letzten Lebensjahren litt sie unter einem starken Altersbuckel in der Hals-Brust-Region (Geßner, 1836). Die krankhaften Veränderungen vor allem im Bereiche der oberen Brustwirbel- und der unteren Halswirbelkörper könnten unter diesem Gesichtspunkt - eine plausible Erklärung finden ${ }^{5}$.

Bringt man einen Schattenriß (Abb.12) sowie ein Halbseitenporträt (Abb.14) mit den entsprechenden Schädelprofilen (Abb.1,15) zur Deckung, zeigt sich allerdings eine auffallende Übereinstimmung (Abb.13,14). In allen Bereichen verlaufen Schädel- und Weichteilkonturen uniform. Beim Schattenriß (Abb.13) ist vor allem im Bereiche der ungewöhnlich gestalteten Nasen- und Stirnpartie die Übereinstimmung beachtlich. Zudem erscheint die Nase hoch und im Halbseitenporträt hoch und schmal. Auch dieses (Abb.14) stimmt in allen Merkmalen gut überein mit dem aus gleichem Winkel photographierten Schädel. Insbesondere die Umrisse der oberen Ränder der großen, rundlichen, leicht nach außen unten geneigten Augenhöhlen und des Hirnschädels im Bereiche der Stirne ver- 
laufen nahezu parallel mit den entsprechenden Weichteilkonturen und sind in allen Einzelheiten mit dem Halbseitenporträt in Übereinstimmung.

Faßt man die für die Beurteilung wichtigen Faktoren unter Berücksichtigung der mangelhaften Angaben zur Person Frau Lavaters zusammen, so machen es besonders die Profil- und Halbprofilvergleiche wahrseheinlich, daß es sich bei den vorliegenden Gebeinen um diejenigen von Frau Anna Lavater-Schinz handelt.

Gegen diese Annahme allerdings spricht die Tatsache, daß Frau Lavater am 27. September 1815 im Kreuzgang der Fraumünster-Kirche beigesetzt wurde und es bis jetzt nicht gelungen ist, nachzuweisen, daß die Gebeine von Frau Lavater vielleicht zwischen 1894 und etwa 1912 zur Zeit der Umbauten und Neubauten am heutigen Stadthaus - exhumiert und im Ehrengrab ihres Gatten neu beigesetzt worden sind $^{6}$.

Gleichzeitig muß die Frage nach dem Verbleib der sterblichen Reste von J. C. Lavater vorläufig ungeklärt bleiben. Die Beschreibung von Lavaters Schädel aus der NZZ $(1882$, s.o.) läßt vermuten, daß damals Lavaters Gebeine tatsächlich in der Obhut der Kirchenpflege St. Peter gewesen sind. Da es sich bei Lavater um einen europäisch bekannten Physiognomen mit ausgesprochen markanten Gesichtszügen (s. z. B. Abb.6) gehandelt hat, ist daran zu denken, daß seine Gebeine - insbesondere sein Schädel - den Weg, den die Schädel so mancher berühmter Europäer gegangen sind (Henschen, 1966), in ein phrenologisches Kabinett genommen haben könnten.

\section{Anmerkungen}

${ }^{1}$ Herrn Dr. Ulrich Ruoff vom Büro für Archäologie der Stadt Zürich danke ich für die Überlassung des Skelettmaterials und für die gewährte Unterstützung.

${ }^{2}$ Ich danke Herrn Dr. Imre A. Lengyel (Budapest) herzlich für die Untersuchungen, die er an einem Knochenstück des Oberschenkels des vorliegenden Skelettes durchgeführt hat und über deren Resultate er im Anhang berichtet.

${ }^{3}$ Frau PD Dr. med. Esther Fischer-Homberger vom Medizinhistorischen Institut der Universität Zürich danke ich für die Hilfe bei der Ausdeutung des Sektionsberichtes.

${ }^{4}$ Herrn Dr. Gustav Solar (Graphische Sammlung der Zentralbibliothek Zürich) danke ich für seine hilfreichen Bemühungen bei der Auswahl und Bestimmung der Bilder.

${ }^{5}$ Herrn Prof. Dr. Erwin Uehlinger vom Pathologischen Institut der Universität Zürich danke ich für seine Mitwirkung.

${ }^{6}$ Herrn Pfr. Berchtold Trümpy von der Sankt-Peter-Kirche sowie Herrn Werner Pestalozzi (Gotthardstraße 49, Zürich) danke ich für ihre tatkräftige Unterstützung bei der Suche nach verwertbaren Hinweisen. 


\section{Literaturverzeichnis}

Bach, H., Zur Berechnung der Körperhöhe aus den langen Gliedmaßenknochen weiblicher Skelette. Anthrop. Anz. 29 (1965) 12-21.

Bodemann, F. W., J.C.Lavater, sein Lebensende und sein Glaubensbekenntnis auf dem Sterbebett, F. Andreas Perthes, Gotha 1856.

Breitinger, E., Zur Berechnung der Körperhöhe aus den langen Gliedmaßenknochen. Anthrop. Anz. 14 (1937) 249-274.

Gerassimov, M.M., Ich suchte Gesichter, Bertelsmann Verlag, Gütersloh 1968.

Geßner, G., Wahre Züge aus dem Bilde einer Stillen auf dem Lande, Steinersche Buchhandlung, Winterthur 1836, 2. Aufl.

Henschen, J., Der menschliche Schädel in der Kulturgeschichte, Springer Verlag, Berlin 1966.

Lavater, J. C., Physiognomische Fragmente zur Beförderung der Menschenkenntniß und Menschenliebe. 4 Versuche, Leipzig und Winterthur 1775-1778.

- Essays on physiognomy, designed to promote the knowledge and the love of mankind, London 1792.

- Nachricht von einem fatalen Vorfall den Pfarrer Lavater betreffend, den 26.9.1799. Zentralbibliothek Zürich, Sp $180 \mathrm{~d}$ (Varia).

Lengyel, I. A., Laboratory examination of the skeletal remains from J. C. Lavater's grave. Gesnerus 33 (1976) 281-284.

Martin, R., Saller, K., Lehrbuch der Anthropologie, Fischer Verlag, Stuttgart 1957.

Nemeskéri, J., Harsani, L., Acsadi, G., Methode zur Diagnose des Lebensalters von Skelettfunden. Anthrop. Anz.14 (1960) 70-95.

Neue Zürcher Zeitung, 6. Januar 1882, Lokales.

Sektionsbericht: Lavaters Section. Druck unbekannter Herkunft, in: Über Lavaters Krankheit und Tode 1801 (Handschriftenabteilung der Zentralbibliothek Zürich, Familienarchiv Lavater, Ms 137).

\section{Summary}

Johann Caspar Lavater (1741-1801), parson of the St.Peter church in Zürich, famous for his "Essays on Physiognomy" and his friendship with J. W. Goethe, was on the 26 th of September 1799 hit in his right thorax by a bullet, which was fired from a Swiss soldier. He never recovered and died from his wounds $5 / 4$ years later, the first of January 1801. He was buried at the St. Anna cemetery. This cemetery was cancelled in 1881 and the bones of Lavater were exhumed and reburied at the northern wall of the St.Peter church in a grave of honour.

As the St.Peter church was restored (1970-1974) this grave was opened and the bones were given to the Anthropological Institute of the University of Zürich for further investigations which revealed the surprising result that the bones belonged to a small woman. The contours of her skull showed great similarities to the portraits of Lavater's wife, Anna Lavater-Schinz (1747-1815). What happened to the bones of J. C. Lavater remains a mystery.

Dr. Hans-Ueli Fritz Etter, Anthropologisches Institut

Künstlergasse 15, 8001 Zürich 


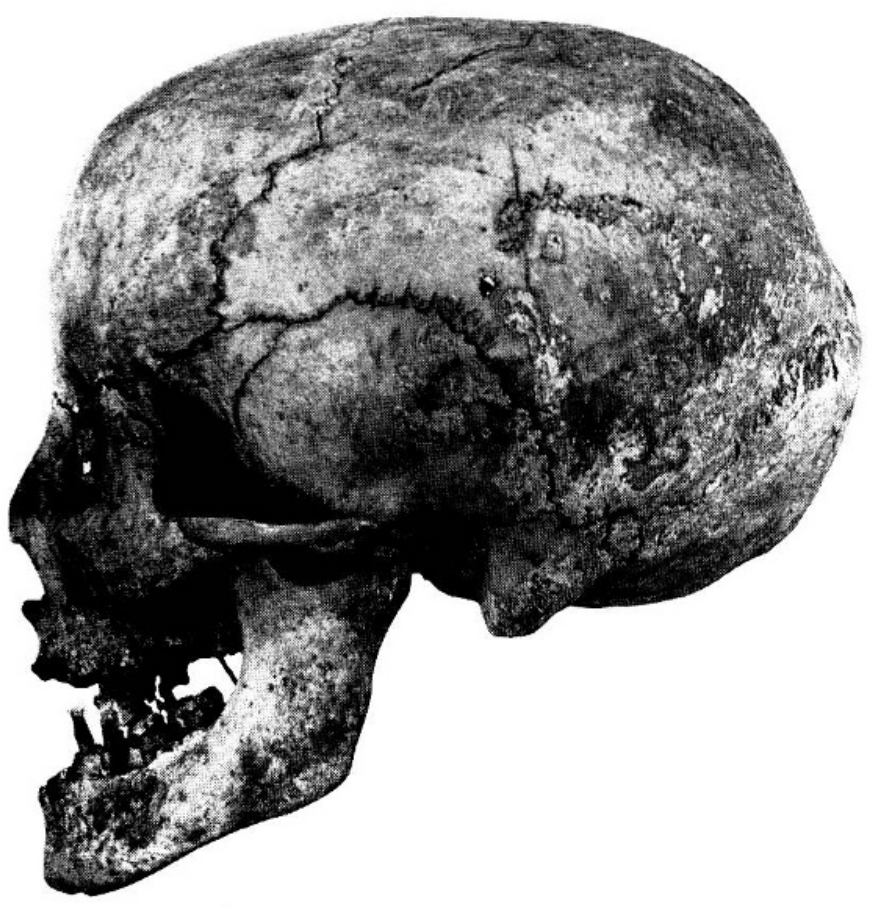

Abb. 1

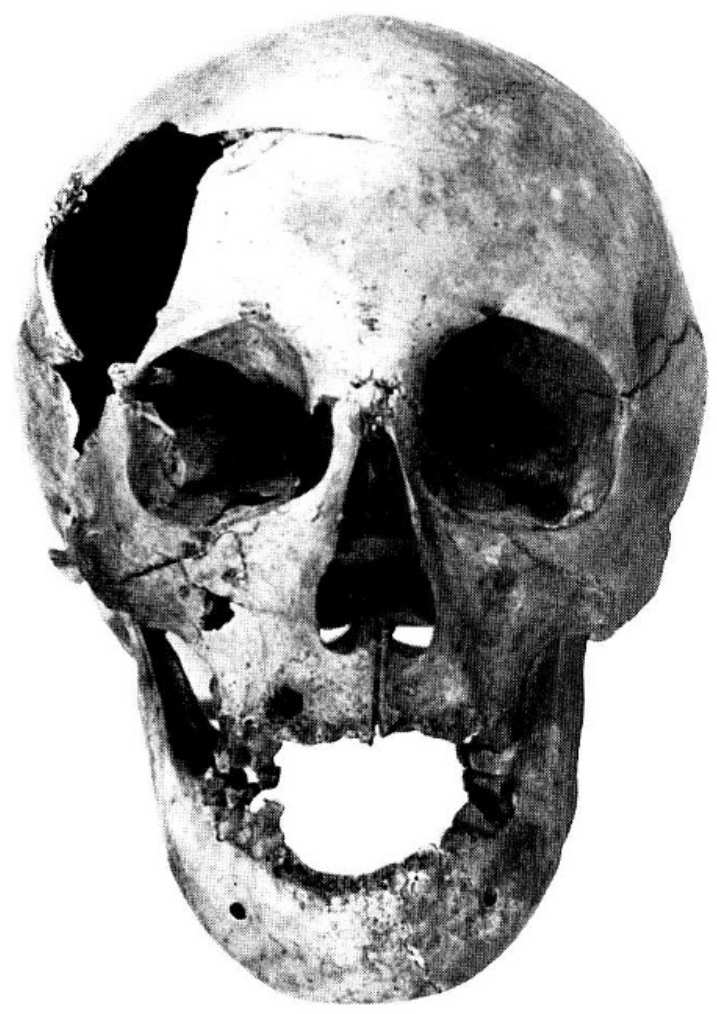

Abb. 2

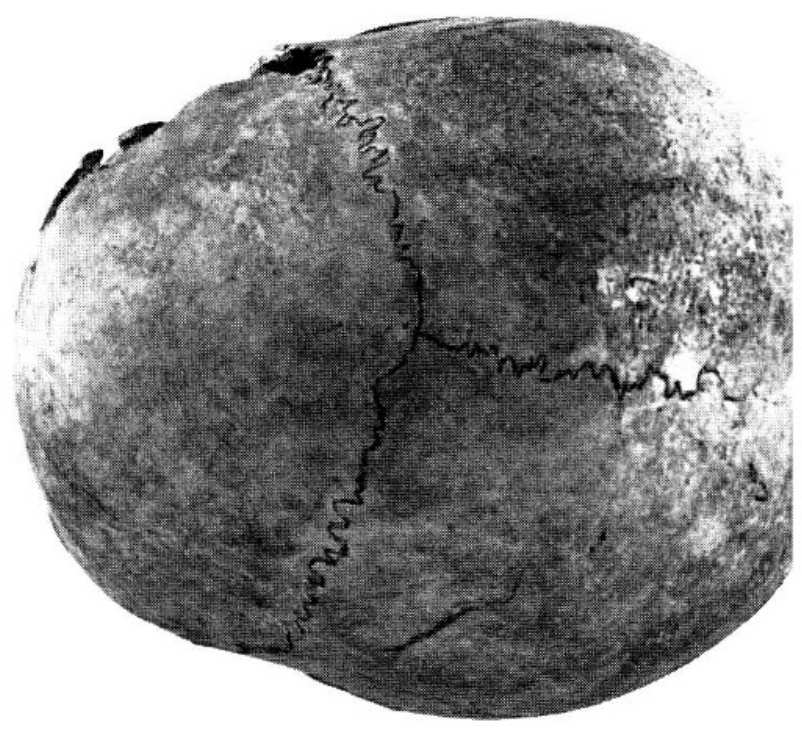

Abb. 3

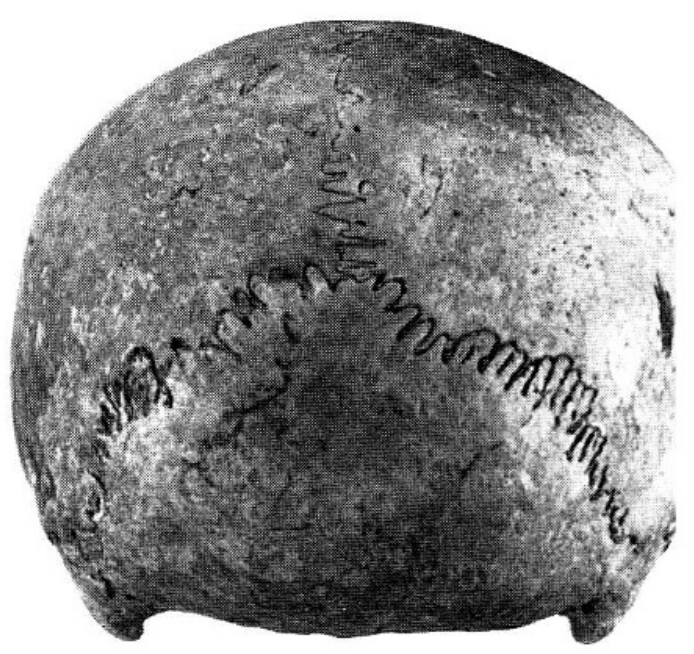

Abb. 1-4. Ansichten des Schädels aus dem Grabe J. C. Lavaters an der Nordmauer der Sankt-Peter-Kirche, Zürich 


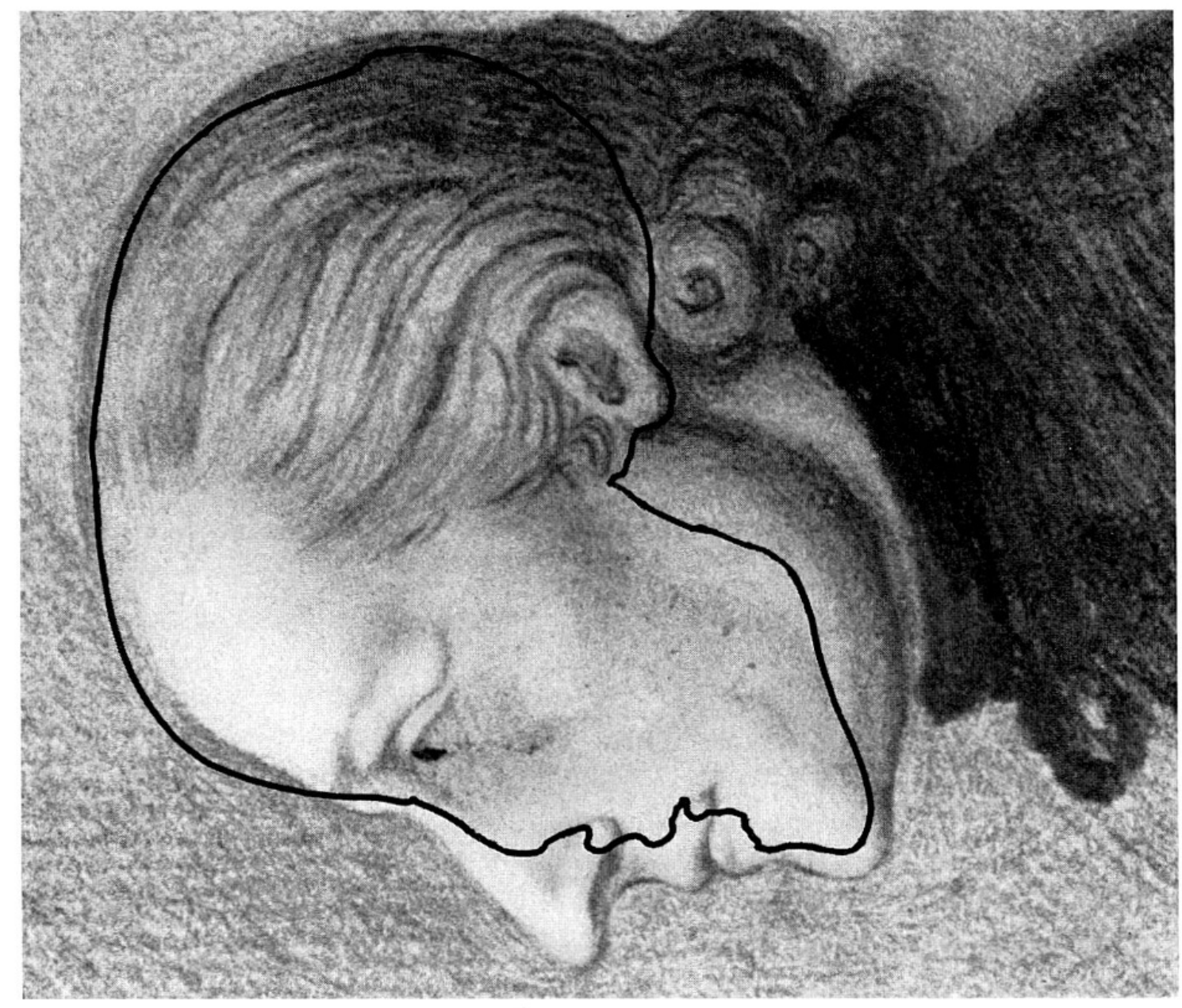

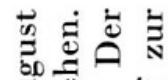

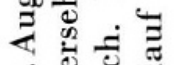

官〉

둴

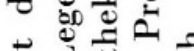

氖

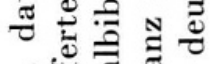

की

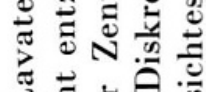

تِ

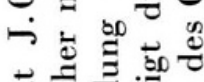

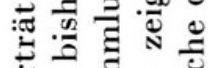

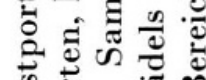

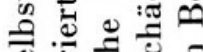

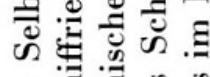

웡 형

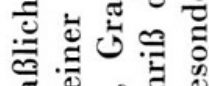

约

$\underline{\exists} \Xi$

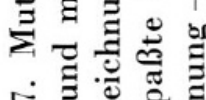

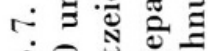

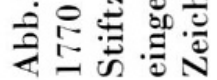

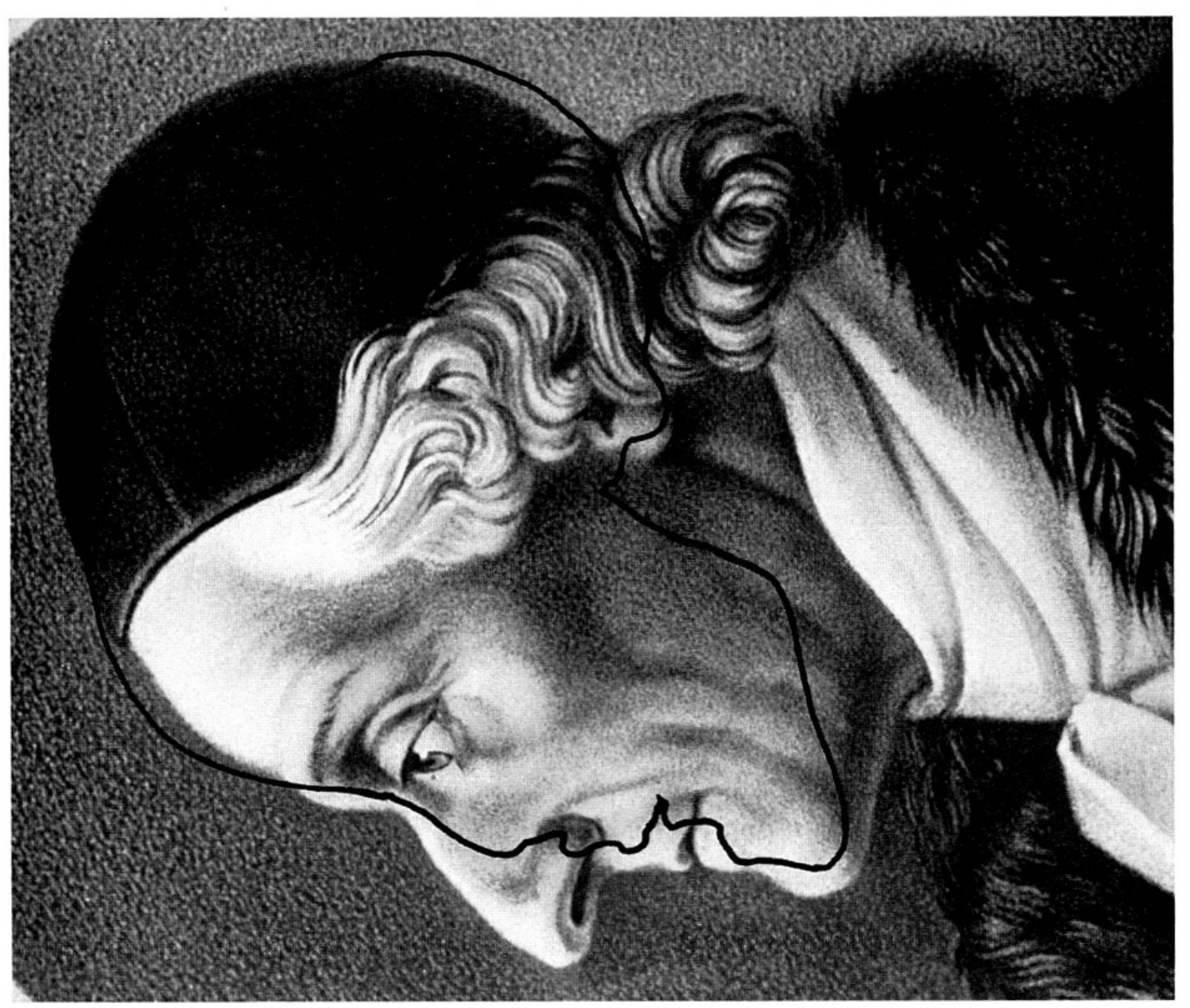

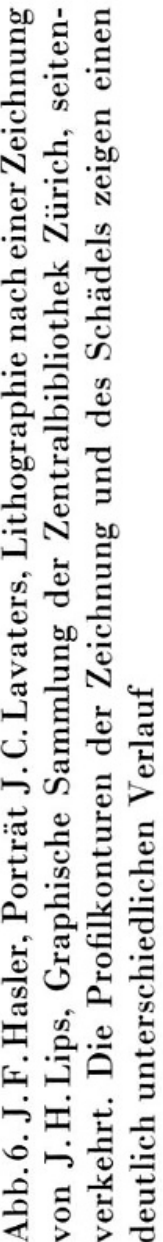




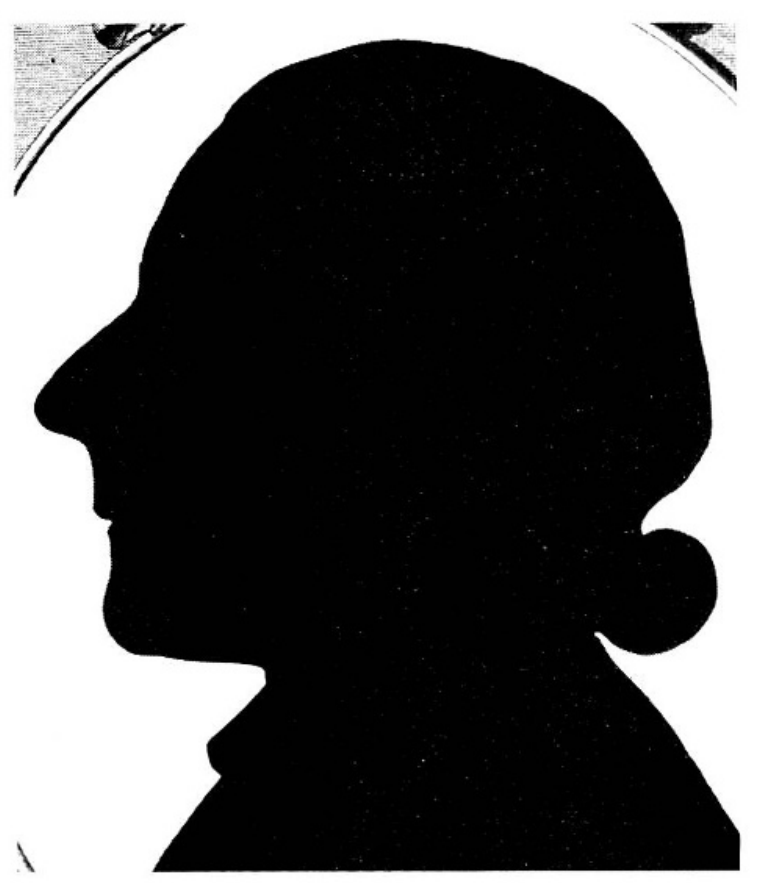

Abb. 8. Schattenriß J.C.Lavaters aus seinen Physiognomischen Fragmenten, englische Ausgabe (1792), Band 2, nach S.226

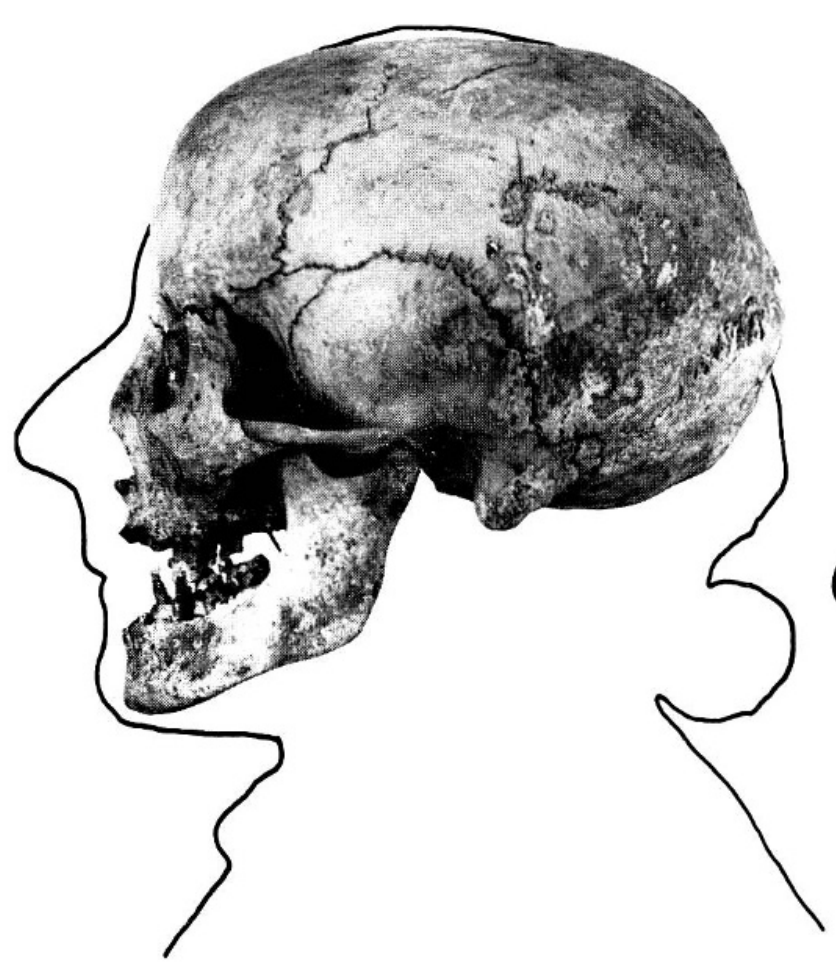

Abb. 9. Die Profilkonturen zeigen deutliche Unterschiede zwischen Schädel und Schattenriß (Abb. 8)

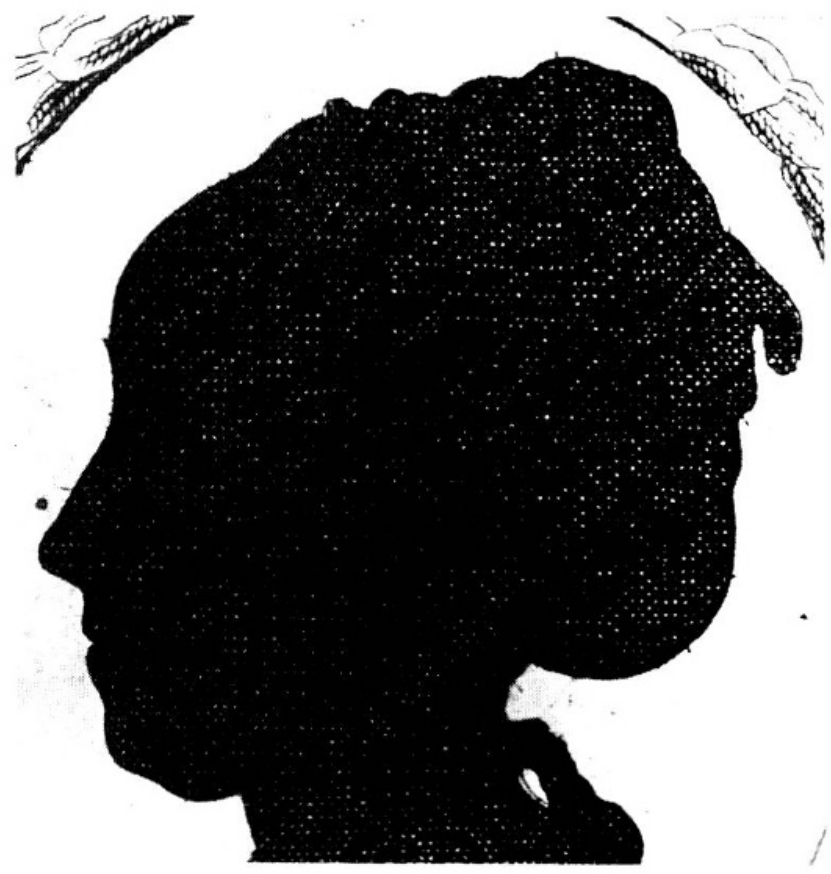

Abb. 12. Schattenriß von J.C. Lavatess Gemahlin Anna Lavater-Schinz aus dem 4. Band (S.337) der Physiognomischen Fragmente (1778), seitenverkehrt

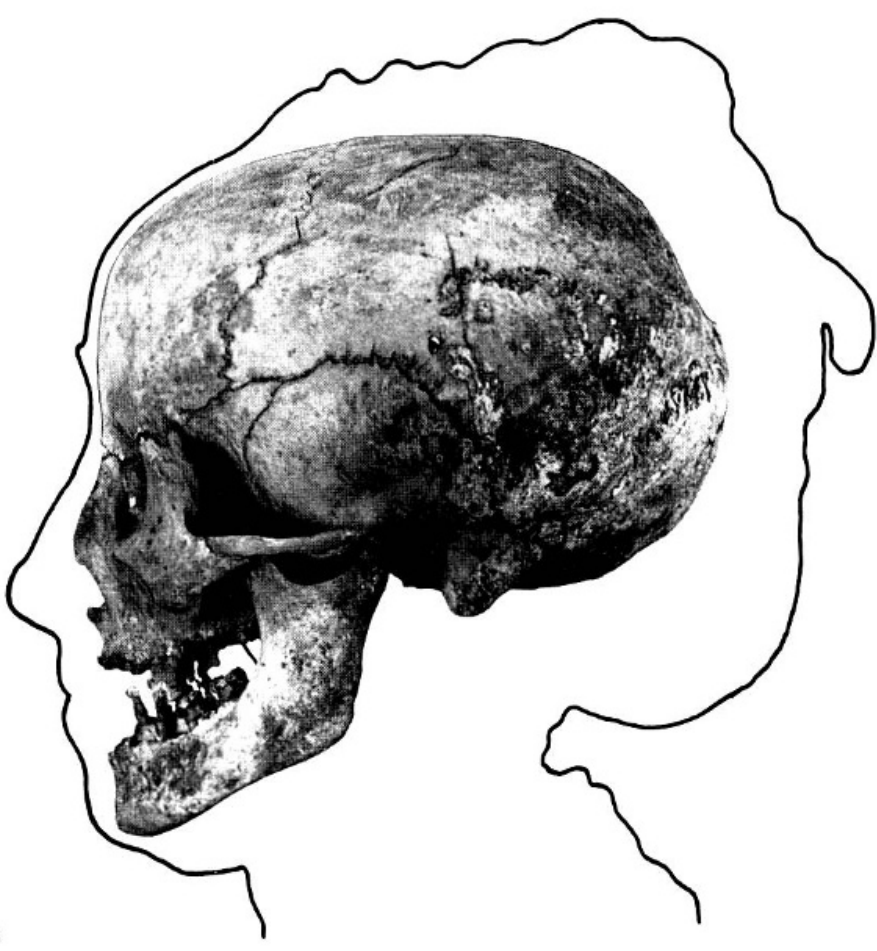

Abb. 13. Die Profilkonturen des Schädels zeigen einen hohen Grad an Ủbereinstimmung mit den Profilkonturen des Schattenrisses (Abb. 12) 


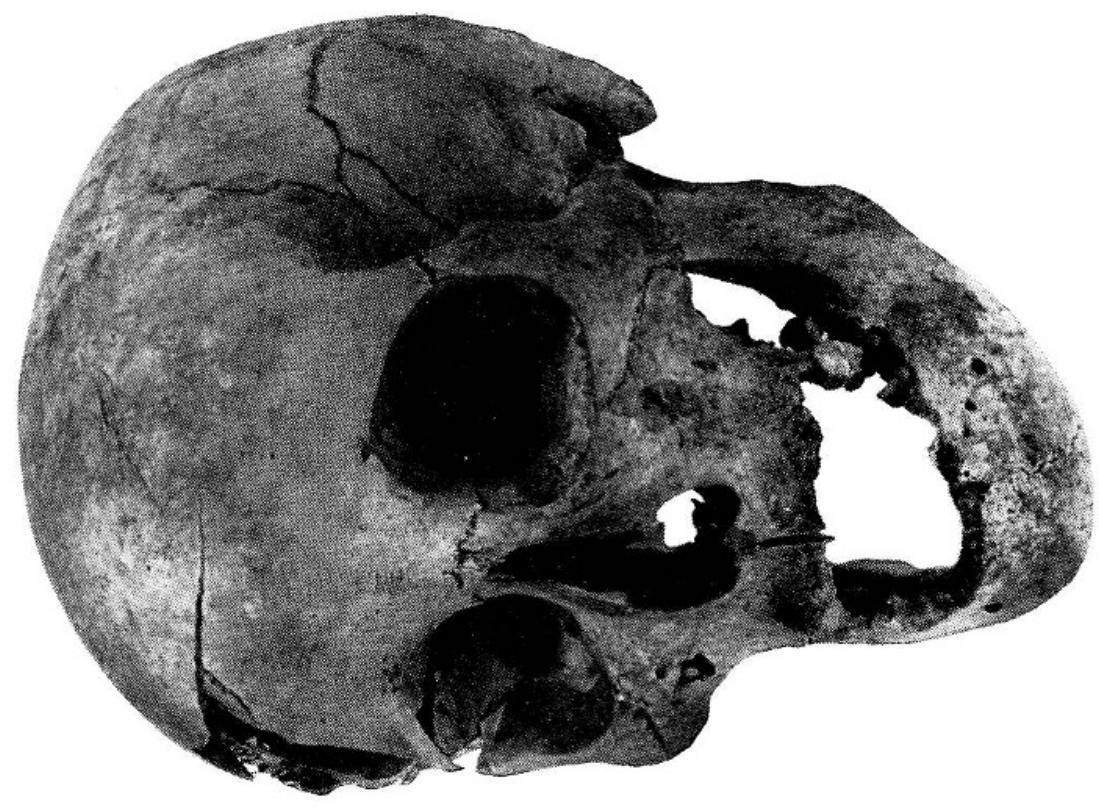

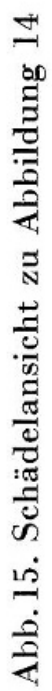

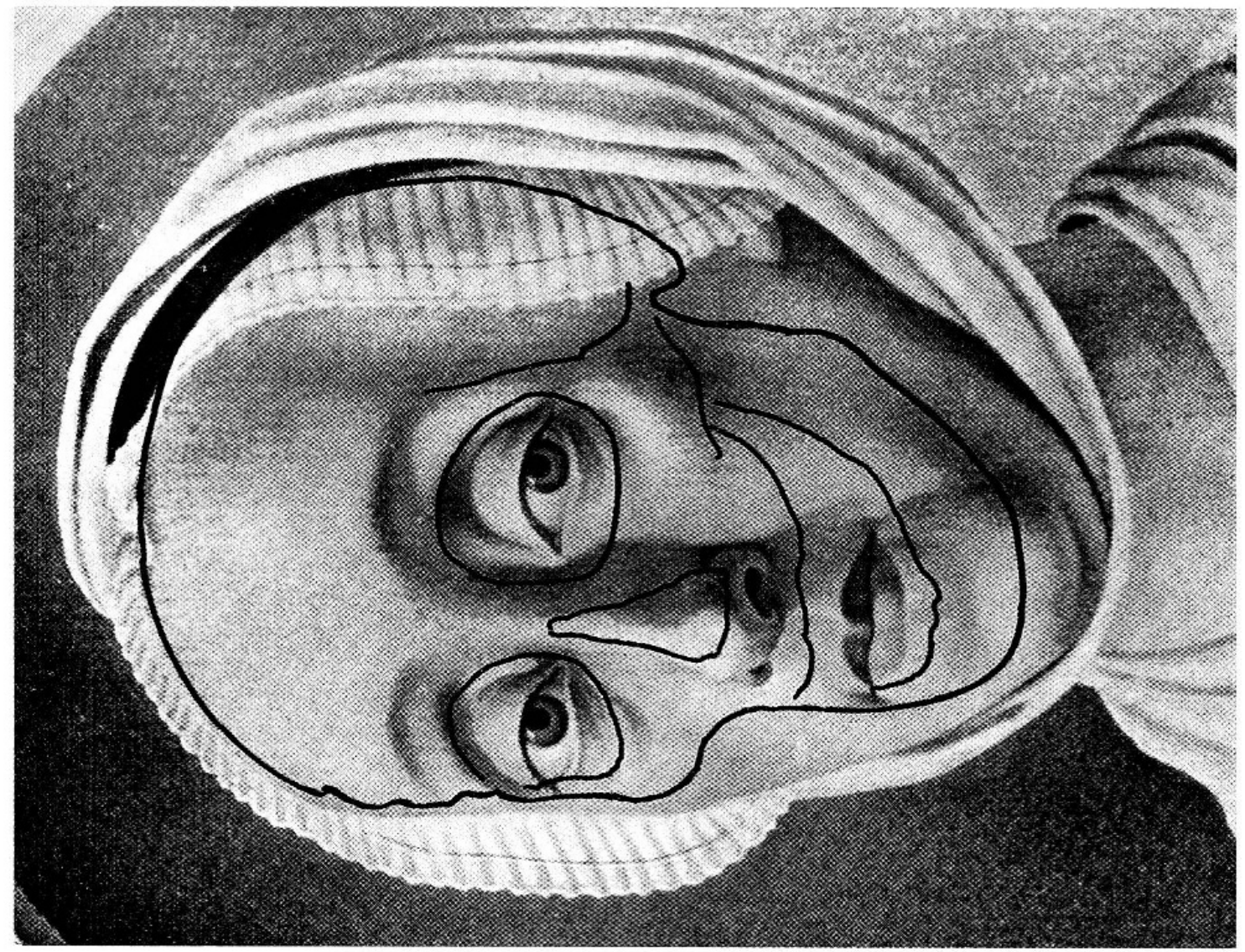

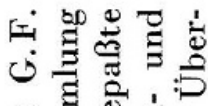

을 हैं

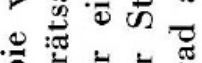

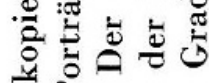

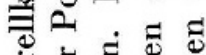

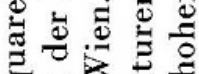

한혀

跣

츠

군

究

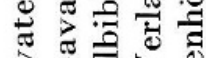

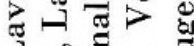

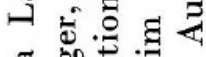

药

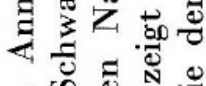

की

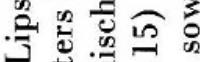

可空递焉

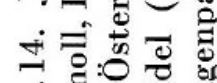

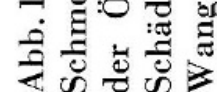




\title{
Anhang
}

\section{Laboratory examination of the skeletal remains}

\author{
from J. C. Lavater's grave
}

By Imre A. Lengyel

I have received a piece of human bone from the Anthropological Institute of the Zürich University - through the kind mediation of professor János Nemeskériin order to try to gain further results concerning the problem of the skeletal remains of the individuum who had been found in the grave of J.C. Lavater, in course of the reconstruction of the St. Peter church in Zürich (Etter 1976).

\section{Material and method}

The sample (14.54 g of weight) was cut off from the shaft of the thigh-bone. Its substance was well preserved and cleaned from contaminations.

The laboratory method used (Lengyel, Nemeskéri 1963; Lengyel 1968), is based on the chemico-analytical (1.), serological (2.) and histological (3.) examination of the bone tissue.

1. The chemico-analytical examinations, carried out on grinded bone, consist of the following three fundamental groups of procedures:

A. Determination of water content:

a) Determination of the quantity of the physically absorbed humidity;

b) Determination of the quantity of the chemically bounded water;

c) Determination of the quantity of the materials burnt out jointly by course of incineration (e.g., crystalline water $\rightarrow \mathrm{H}_{2} \mathrm{O}$ steam, $\mathrm{P} \rightarrow \mathrm{PO}_{5}, \mathrm{CO}_{3}{ }^{2-}$ and carbohydrates $\rightarrow \mathrm{CO}_{2}$ gas, etc.)

B. Determination of organic constituents:

a) Nitrogen containing organic substances:

1. Total nitrogen content

2. Amount of "non-protein" nitrogen

3. Water-soluble organic fraction

4. Amount of protein-polysaccharide complex

5. Amount of collagen

6. Amount of "resistant proteins"

b) Nitrogen-free organic constituents :

1. Citrate content

2. Polysaccharides

3. Lipides

4. Carbonate salts (e.g., $\mathrm{CaCO}_{3}$ in form of $\mathrm{CO}_{2}$ gas, etc.) 
C. Determination of inorganic constituents:

a) Calcium content

b) Total amount of phosphorus

c) Magnesium content

d) Iron content

e) Some other inorganic elements (e.g., $\mathrm{Na}, \mathrm{K}, \mathrm{Cl}, \mathrm{S}$, etc.)

2. The serological examination of the bone sample, in the literal sense of the word, the determination of the ABO blood group property of the late individual, is carried out according to the modified fluorescent antibody method (Lengyel 1975).

3. The histologic examination of the bone tissue, striving for the diagnose of the possible pathologic changes, means:

a) routine staining methods (e.g., H.e., Azan, Schmorl's method, silver impregnation, etc.); and

b) histochemical procedures (e.g., metachromatic staining reaction, peroxydase reaction, etc.).

The results gained are compared, by the help of statistical computations, to those of fresh dissecting-room samples with known case history, in order to draw inferences concerning the biological parameters (sex, age at death, blood group, etc.) of the late individual examined (Nemeskéri, Lengyel 1963).

However, there are two unknown factors in our system of comparisons: first, the case history of the individual whose mortal remains are inspected; second, the consequences of decompostion which affect the chemical structure of the bone tissue and may, therefore, vitiate the results of our analyses. (Decomposition is understood to mean all biological, chemical and physical influences to which the skeleton is exposed from the individual's death to the time of the laboratory examination.)

Anamnesis of the individual whose bone remains are examined cannot be ascertained without first eliminating the unknown influences of decomposition. It seems justified to assume anatomically identical bones, dating from the same chronological age, interred in the same kind of soil and excavated from the same depth, have been exposed to roughly identical decomposing agents acting in the same manner and with the same efficiency.

\section{Results (selected) of the laboratory examination}

1. Citrate:

2. Collagen:

1.07 per cent by weight

3. Carbonates:

4. Phosphorus:

5. Calcium:

3.75

12.95

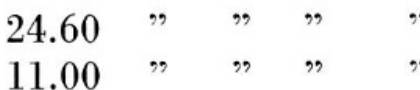

6. Water (total):

\} $\mathrm{Ca} / \mathrm{P}: 1.8996$

7. Protein-polysaccharide complex : 0.12 per cent by weight

8. Blood group property: "0" 


\section{Discussion}

In general, the values, obtained by the chemical analysis of the bone sample in question are in a close relation to those of our fresh standard series. Most of the present laboratory results can be fitted among the values of the main sex and age symptoms of our standard series, with the exception of the total water content and the amount of the protein polysaccharide complex (Table 1). The relative diminution both of these two constituents can be explained as the consequence of the postmortal decomposition of the bone tissue.

The probable sex of the late individual examined-according to the evidence of the mean citrate values of our standard series (Table 1) - by all means was female.

Table 1: Mean values of the standard dissecting-room series $(\mathrm{N}=700)$

The values are calculated on dried, fat-free bone material; in weight per cent

\begin{tabular}{|c|c|c|c|c|c|c|c|c|}
\hline $\begin{array}{l}\text { Age } \\
\text { groups }\end{array}$ & Collagen & Carbonate & Phosphorus & Calcium & $\begin{array}{l}\text { Total } \\
\text { Water }\end{array}$ & $\mathrm{Ca} / \mathrm{P}$ & $\begin{array}{l}\text { Citrat } \\
\text { male }\end{array}$ & $\begin{array}{l}\mathrm{e} \\
\text { female }\end{array}$ \\
\hline $0-5$ & 19.65 & 1.72 & 15.08 & 21.57 & 18.73 & 1.43 & 0.501 & 0.527 \\
\hline $6-10$ & 20.03 & 1.82 & 14.90 & 22.36 & 18.73 & 1.50 & 0.513 & 0.531 \\
\hline $11-15$ & 20.57 & 1.95 & 14.88 & 23.06 & 18.71 & 1.55 & 0.612 & 0.881 \\
\hline $16-20$ & 20.84 & 2.16 & 14.66 & 23.45 & 18.55 & 1.60 & 0.615 & 0.997 \\
\hline $21-30$ & 20.01 & 2.44 & 14.35 & 24.10 & 18.05 & 1.68 & 0.678 & 1.015 \\
\hline $31-40$ & 19.77 & 2.92 & 13.76 & 24.76 & 17.66 & 1.80 & 0.515 & 1.035 \\
\hline $41-50$ & 19.41 & 3.00 & 13.44 & 24.82 & 17.35 & 1.85 & 0.750 & 1.079 \\
\hline $51-60$ & 19.23 & 3.64 & 12.98 & 24.39 & 17.10 & 1.88 & 0.875 & 1.100 \\
\hline $61-70$ & 18.74 & 4.01 & 12.92 & 24.54 & 17.01 & 1.90 & 0.901 & 1.092 \\
\hline $71-x$ & 18.32 & 4.56 & 12.74 & 24.20 & 16.86 & 1.90 & 0.976 & 1.020 \\
\hline $\mathrm{N}=700$ & $M=19.66$ & 2.82 & 13.97 & 23.73 & 17.89 & 1.71 & 0.694 & 0.928 \\
\hline
\end{tabular}

Concerning her age at death, three of the four chemical age symptoms $\left(\mathrm{CO}_{3}\right.$, $\mathrm{P}, \mathrm{Ca}$ ) are referring to the biological age group between $61-70$, however, on the strength of the evidence of the fourth age symptom (bone collagen) she might be fairly younger: between $41-50$ years (Table 1). This seemingly contradictional result can be explained by the histological contexture of her bone tissue. The collagen fibers are denser, rougher and more bulky (demonstrated by silver impregnation) than in normal cases. This unexpected increase of the collagen content, thus, may refer to a pathological background.

From a serological point of view, within the system of "secretor" she belongs to blood group " 0 " (see: protein polysaccharide complex content in: Lengyel 1975).

At last, but not least, I must confess, that the conclusions drawn from the numerical values of the laboratory examinations of the mentioned bone sample have to be accepted with cautious reservation!-I was given a single piece of human bone, for the purpose of laboratory analysis and, as a natural consequence 
of it, not any kind of statistical computations could be applied. Thus, the conclusions described above are based exclusively on my own experiences, instead of statistical methods.

However, in spite of these precautions, I hope that the results of the laboratory analyses are in agreement with the results of the anthropometrical methods, as well as, with the facts of the history. More over, I hope, that these results would supply with further contributions to the biological portrait of the late Mrs. Anna Lavater-Schinz.

\section{Bibliography}

Etter, H.-U.F. (1976), Die Gebeine aus J. C. Lavaters Grab an der Nordmauer der St.-Peters-Kirche. Zeitschrift für Schweizerische Archäologie und Kunstgeschichte 33 , S. $45 \mathrm{f}$.

Lengyel, I. (1968), Biochemical aspects of early skeletons. In: Brothwell, D. R. (edit.): The Skeletal Biology of Earlier Human Populations, Pergamon Press, Oxford/London, S. 271-288.

- (1975), Paleoserology, Akadémiai Kiadó, Budapest.

Lengyel, I., Nemeskéri, J. (1963), Application of biochemical methods to biological reconstruction. Zeitschrift für Morphologie und Anthropologie 54, S.1-56.

Nemeskéri, J., Lengyel, I. (1963), Ujabb biológiai módszerek a történeti népességek rekonstrukciójában. M.T.A. Biol. Tud. O. közl. VI. 3-4, S. 333-357.

Dr. Imre Lengyel

1023. Budapest, II

Árpád fejedelem utja 44. III./2

Hungary 